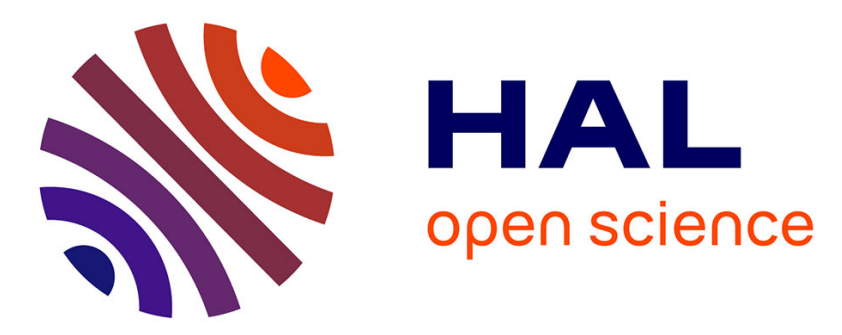

\title{
Lower jaw reconstruction and dental rehabilitation after war injuries: the experience of Paul Tessier in Iran in the late 1980s
}

\author{
François Simon, Serge Ketoff, Benjamin Guichard, S Anthony Wolfe, \\ Jean-François Tulasne, Chloé Bertolus, Roman Hossein Khonsari
}

\section{To cite this version:}

François Simon, Serge Ketoff, Benjamin Guichard, S Anthony Wolfe, Jean-François Tulasne, et al.. Lower jaw reconstruction and dental rehabilitation after war injuries: the experience of Paul Tessier in Iran in the late 1980s. Journal of Cranio-Maxillofacial Surgery, 2015, 43 (5), pp.606-610. 10.1016/j.jcms.2015.02.015 . hal-01132863

\section{HAL Id: hal-01132863 https://hal.sorbonne-universite.fr/hal-01132863}

Submitted on 18 Mar 2015

HAL is a multi-disciplinary open access archive for the deposit and dissemination of scientific research documents, whether they are published or not. The documents may come from teaching and research institutions in France or abroad, or from public or private research centers.
L'archive ouverte pluridisciplinaire HAL, est destinée au dépôt et à la diffusion de documents scientifiques de niveau recherche, publiés ou non, émanant des établissements d'enseignement et de recherche français ou étrangers, des laboratoires publics ou privés. 


\section{Lower jaw reconstruction and dental rehabilitation after war injuries: the experience of Paul Tessier in Iran in the late 1980s}

\section{Authors :}

François SIMON ${ }^{1}$; Serge $\mathrm{KETOFF}^{1}$; Benjamin GUICHARD ${ }^{2}$; S Anthony WOLFE $^{3}$; JeanFrançois TULASNE ${ }^{4}$; Chloé BERTOLUS ${ }^{1}$; Roman Hossein KHONSARI ${ }^{1}$

${ }^{1}$ : AP-HP, Hôpital Pitié-Salpêtrière, Service de chirurgie maxillo-faciale, Paris, F-75013, France ; UPMC Univ Paris 06, F-75005, Paris, France ;

${ }^{2}$ : Hôpital Charles-Nicolle, Service de chirurgie maxillo-faciale, Rouen, F-76038, France ; Université de Rouen, Rouen, France ;

3: Plastic and Reconstructive Surgery, Miami Children's Hospital, 3100 SW 62 Avenue, ACB \#2230, Miami FL

${ }^{4}$ : Private practice, 26 avenue Kléber, 75116 Paris, France

\section{Corresponding author:}

François SIMON, M.D.

AP-HP, Hôpital Pitié-Salpêtrière, Service de chirurgie maxillo-faciale

47-83 Boulevard de l'Hôpital, 75013 Paris (France)

$+33686327111$

fsimon05@gmail.com 


\begin{abstract}
Iraq-Iran war resulted in more than 400,000 people requiring prolonged medical care in Iran. An international team of prominent reconstructive surgeons led by Paul Tessier, the founder of craniofacial surgery, was invited to Iran during the war by official organizations entitled to support war victims. This team provided up-to-date oral and maxillofacial rehabilitation to patients with severe trauma defects in the lower third of the face. We collected the medical notes of 43 patients operated on by the Tessier team in Iran in the 1980s (files property of AFCF). The parameters we collected were: age of the patient, nature of the trauma (when available), previous procedures, number of implants placed (mandibular and maxillary), associated procedures (bone grafts, soft-tissue procedures, orthognathic surgery). A protocol based on soft-tissue rehabilitation using local flaps, parietal or iliac bone grafts and implant placement 6 months later was used in all patients. Paul Tessier's approach emphasizes the importance of keeping high standards of care in difficult situations and maintain standard protocols.
\end{abstract}

Keywords: Iran; reconstruction; Tessier; tooth implant; war injury 
Introduction: The Iraq-Iran war lasted for 8 years and caused more than 200,000 casualties on the Iranian side. This very long conflict affected both the military (75\%) and the civilian (25\%) populations. Up to $75 \%$ of victims were 16 to 25 years of age and mandibular defects were the most common maxillofacial injury (Akhlaghi and Aframian-Farnad, 1997; Salamati et al., 2013). Two organizations are entitled to provide support to war victims: the Foundation of Martyrs Affairs (FMA) and the Janbazan Affairs Organization (JAO). According to the statistics of the JAO in 2007 , nearly 400,000 people required prolonged medical care as a consequence of war injuries (Zargar et al., 2007; Noorbala, 2010). The effects of the Iraq-Iran war are thus a major health issue in both countries 25 years after the ceasefire (Zargar et al., 2007; Salamati et al., 2013).

Paul Tessier (1917-2008) was a prominent, French plastic surgeon who made major breakthroughs in the field of craniofacial reconstruction (Wolfe, 1997; Jones, 2008; Watts, 2008). With a team including Jean-François Tulasne (Paris, France), David Matthews (Charlotte, USA), Joe Murray (Boston, USA), Fernando Ortiz Monasterio (Mexico City, Mexico), Yvon Raulo (Paris, France) and Luigi Clauser (Ferraro, Italy), he led several surgical missions to post-war Iran in order to operate on patients requiring mid- and lower face reconstruction. These missions were funded by the JAO and each member of the team received a reimbursement of $\$ 15,000$ per week (Wolfe, 2012).

During these missions, he applied a rigorous protocol based on primary soft-tissue procedures, bone graft and implant placement, characterized by surprisingly extensive bone reconstruction without using free tissue transfers. Here we report the placement of 204 implants in 43 patients with war injuries and detail the procedures used by Tessier and his international team in wartime Iran.

Material and methods: We collected data on the patients operated on by Paul Tessier and his team in post-war Iran from the Paul Tessier collection stored at the Amiens University 
Hospital (property of the Association Française des Chirurgiens de la Face). Tessier took precise notes of the consultations and surgical procedures including photographs of the patients and radiology.

We found 43 patients operated on by Tessier in Iran from 1976 to 1993 for war injuries. The collected parameters were: age of the patient, nature of the trauma (when available), previous procedures, number of implants (mandibular and maxillary) placed by Tessier and his team, associated procedures (bone grafts, soft-tissue procedures, orthognathic surgery). The techniques used in the documents were then compared with techniques used today.

Results: A series of 43 patients presenting various maxillofacial war injuries were operated on and implanted using Brånemark System Mk III implants (Nobel Biocare, Zürich-Flughafen, Switzerland). Wounds were mostly bullet and shell injuries (Table 1). The age of the patients ranged from 23 to 47 years (mean age: 28). The injuries occurred between 1979 and 1987 (mean year: 1985). Patients were subjected to three procedures on average (range: 1-7). All patients had undergone 1-12 prior surgeries with other surgical teams. 204 implants were put in place (68 maxillary and 136 mandibular). A total of 24 bone graft procedures were performed on 19 patients (44\%); in most cases these were from iliac crest (15) and sometimes parietal grafts (4) (example in Fig. 1). All 204 implants were put in place 6 months after bone grafting. Various soft-tissue procedures were required for 15 patients (Table 2). The lips were chiefly reconstructed with commissuroplasties (7 cases) and the cheek using Baron-Tessier island flaps ( 3 cases) or rotation flaps ( 2 cases) (examples in Fig. 2 and 3). Other procedures included two parietal expanders, three external canthopexies and one rhinoplasty. Associated orthognathic procedures were also performed: six Le Fort I, one hemi-Le Fort I, three genioplasties and one sagittal split of the mandible. Three patients entered an orthodontic rehabilitation program in collaboration with the local dental school. Control radiographs were orthopantomogram and lateral and frontal cephalograms. Fifteen cases had CT-scans, of 
which three benefited from 3D reconstruction. In most patients Tessier used the same protocol with initial soft tissue and bone reconstruction followed by implants 6 months later.

Precise description of the surgical procedure is given for a very complex case, in Tessier's own words, “"une des reconstructions post-traumatiques les plus intéressantes, les plus instructive et les plus completes d'une carrière de 40 ans", (one of the most interesting, posttraumatic reconstructions, the most instructive and complete case in a 40 year career, Fig. 4). This patient suffered an unknown injury in 1985 with a comminuted maxillary fracture and was first operated on in Iran 5 years later with maxillectomy, Le Fort III and a tongue flap to reconstruct the palate. Tessier and his team (including Tulasne) planned a multi-stage reconstruction with six operations over two years before the first implants. The most important step was the first, with reconstruction of the nose and orbit using parietal bone grafts and reconstruction of the entire palate using the right temporal muscle and its corresponding external cortical parietal bone in one chimeric pedicled flap. The muscle was sutured upwards to the nasal cavity and the palate mucosa was sutured to the concave parietal bone. Two extra operations were needed at 15 days and 4 months with iliac bone grafts to stabilize the structure. Other operations at 6,12 and 18 months enabled the reconstruction of the zygomatic bone and arch using parietal grafts, of the premaxilla using iliac grafts and cancellous grafts to further stabilize the maxilla. Finally after 2 years, eight maxillary and four mandibular implants were successfully put in place.

One of the most interesting aspects of Tessier's notes are his comments after each procedure on the techniques he used, what he could have done better and the next steps to be made. For example in this case after the first procedure he emphasizes the importance of having X-rays and photos before each operation, but also how his peroperative decision to remove the zygomatic arch enabled him to better place the chimeric temporal flap. He is also self-critical and lists improvements, such as in this case how the temporal muscle flap was bulging in the 
orbit and how he should have better separated it from the remaining temporal muscle. Lastly, he also comments on similarities with previous operations, in this case on the chimeric temporal flap and how the bone seems to be directly vascularized by the temporal muscle.

Discussion: The Iraq-Iran war resulted in numerous severe craniofacial injuries. In the 1990s, lower jaw rehabilitation using implants required an expertise that was brought by Tessier and his team in post-war Iran. At that time, applying a standard protocol based on bone reconstruction and secondary implantation was a pioneering approach. In fact, upper and lower jaw rehabilitation in war-injured patients requires the combination of soft-tissue reconstruction and bone grafts before implant placement (Motamedi and Behnia, 1999; Motamedi et al., 1999; Motamedi, 2003; Sadda, 2003). This series also emphasizes the need for meticulous anticipation in the reconstruction of these complex defects. It shows how Tessier was able to plan and reason in three dimensions (sometimes with the help of innovative 3D scans) step by step until the final stage, an aspect essential to craniofacial surgery. His post-operative comments and self-criticism were also key to his progress and success as a surgeon.

Tessier's approach was to base all procedures on the reconstruction of bony scaffolds. As quoted from one the patient's notes he operated on in Iran: Le fonctionnel est toujours morphologique donc esthétique (Function always derives from morphology and is thus esthetic). Even large mandibular defects from molar to molar were reconstructed using macroplates and numerous bone grafts. Tessier also believed in craniofacial "“autarchy", meaning that he considered the head and neck to be self-sufficient for reconstruction, and preferred when possible to use parietal bone grafts and local reconstructions (Wolfe, 2012). Indeed, as confirmed by the good results in this series and by other authors, iliac and parietal bone grafts seem to be equivalent to fibula free flaps for bone reconstruction and can provide the necessary structure for implants (Mertens et al., 2013). 
Tessier and his team used mostly conventional local flaps such as heterolabial flaps or muscoal flaps for soft tissue reconstruction. However, two methods need to be discussed. For the inner lining of the cheek, the Baron-Tessier platysma flap is preferred in most cases. This technique, offers a reliable large provision of thin pliable skin and muscle equivalent or superior to free flap reconstruction of the inner cheek (Talmant, 1983; Tessier et al., 2011). It is also easy and quick to harvest and does not require a specialized follow-up like free flaps. The other interesting technique specific to these defects in male patients is the visor scalp flap which is used in each case where reconstruction of the beard region was necessary. It is a reliable flap with good esthetic results for upper and lower lip defects in males wearing a beard or moustache. Other advantages are easy harvesting and direct closure of the donor site (Rasse et al., 1999; Hafezi et al., 2002).

The major drawback of this series is the lack of long-term follow-up of the patients, although the short-term (and even mid-term) follow-up available to us in Tessier's notes is more than satisfactory.

Conclusion: Tessier and his team successfully reconstructed this series of patients with craniofacial war injuries in Iran. This was achieved by implementing a strict two-phase protocol starting with bone and soft tissue reconstruction and secondary implant placement 6 months later. Local flaps were always used as well as parietal (if accessible during the operation) or iliac bone grafts. This series emphasizes that humanitarian treatment and especially surgical procedures need to be as simple as possible. 


\section{Acknowledgement}

The authors would like to express their sincere gratitude to the Association Française des Chirurgiens de la Face (AFCF) for granting access to the documents and photos of the Tessier Collection (Centre Hospitalo-Universitaire d'Amiens, Université de Picardie).

\section{Conflict of interest}

The authors do not have any commercial or other association that might pose a conflict of interest. The authors did not have any financial support to write this paper. Written patient consent has been obtained to publish clinical photographs. All authors have viewed and agreed to the submission. 


\section{References}

Akhlaghi, F. and F. Aframian-Farnad: Management of maxillofacial injuries in the Iran-Iraq War. J Oral Maxillofac Surg 55: 927-930, 1997

Hafezi, F., B. Naghibzadeh and A. Nouhi: Facial reconstruction using the visor scalp flap. Burns 28: 679-683, 2002

Jones, B. M.: Paul Louis Tessier: plastic surgeon who revolutionised the treatment of facial deformity. J Plast Reconstr Aesthet Surg 61: 1005-1007, 2008

Mertens, C., C. Decker, M. Engel, A. Sander, J. Hoffmann and K. Freier: Early bone resorption of free microvascular reanastomized bone grafts for mandibular reconstruction - A comparison of iliac crest and fibula grafts. J Craniomaxillofac Surg 2013

Motamedi, M. H.: Primary management of maxillofacial hard and soft tissue gunshot and shrapnel injuries. J Oral Maxillofac Surg 61: 1390-1398, 2003

Motamedi, M. H. and H. Behnia: Experience with regional flaps in the comprehensive treatment of maxillofacial soft-tissue injuries in war victims. J Craniomaxillofac Surg 27: 256-265, 1999

Motamedi, M. H., H. M. Hashemi, M. G. Shams and A. N. Nejad: Rehabilitation of warinjured patients with implants: analysis of 442 implants placed during a 6-year period. J Oral Maxillofac Surg 57: 907-913; discussion 914-905, 1999

Noorbala, A. A.: The organization and management of medical services to injured soldiers across the country and in the battlefields during the Iran-Iraq War. Arch Iran Med 13: 367369,2010

Rasse, M., C. Kermer and G. Undt: The platysma myocutaneous visor flap for intraoral reconstruction. A case report. Int J Oral Maxillofac Surg 28: 377-379, 1999 
Sadda, R. S.: Maxillofacial war injuries during the Iraq-Iran War: an analysis of 300 cases. Int J Oral Maxillofac Surg 32: 209-214, 2003

Salamati, P., S. M. Razavi, F. Shokraneh, S. Mohazzab Torabi, M. Laal, G. Hadjati, et al.: Mortality and injuries among Iranians in Iraq-Iran war: a systematic review. Arch Iran Med 16: $542-550,2013$

Talmant, J. C.: [Use of neck muscle in the correction of facial asymmetry. The Barron-Tessier flap]. Rev Stomatol Chir Maxillofac 84: 283-288, 1983

Tessier, P., D. C. Matthews, D. Kamerer, Jr., F. S. Ciminello, F. Gargano and S. A. Wolfe: Platysma-based myocutaneous clavicular island flap for intraoral reconstruction. Ann Plast Surg 67: S55-69, 2011

Watts, G.: Paul Tessier. Lancet 372: 368, 2008

Wolfe, S. A.: The influence of Paul Tessier on our current treatment of facial trauma, both in primary care and in the management of late sequelae. Clin Plast Surg 24: 515-518, 1997

Wolfe, S. A. In Wolfe SA, A man from Héric. The life and work of Paul Tessier, MD, father of craniofacial surgery Lulu.com, London. 2012

Zargar, M., H. Araghizadeh, M. R. Soroush and A. Khaji: Iranian casualties during the eight years of Iraq-Iran conflict. Rev Saude Publica 41: 1065-1066, 2007 
Table 1. Wound type

\begin{tabular}{l|lllll}
\hline & Shell & Bullet & Grenade & Blunt trauma & Not Available \\
\hline$n$ & 17 & 7 & 1 & 2 & 16 \\
$\%$ & 40 & 17 & 2 & 4 & 37 \\
\hline
\end{tabular}

Table 2. Type of reconstruction before implant

\begin{tabular}{l|lllllll}
\hline & Le Fort 1 & Genioplasty & $\begin{array}{l}\text { Other } \\
\text { hard* }\end{array}$ & Lip & Cheek & Other soft** & $\begin{array}{l}\text { Bone } \\
\text { graft }\end{array}$ \\
\hline$n$ & 6 & 3 & 3 & 9 & 4 & 5 & 24 \\
$\%$ & $14 \%$ & $7 \%$ & $7 \%$ & $21 \%$ & $9 \%$ & $11 \%$ & $56 \%$ \\
\hline
\end{tabular}


Fig. 1: Lower jaw reconstruction using parietal bone grafts. (a) Initial presentation after two bone grafts performed before Tessier's procedures. (b) Right parietal cortical and cancellous bone grafts: right lower border of the mandible $(7 \mathrm{~cm})$, midline (lower border of the chin) and paramedian on both sides of the chin; the space between the grafts was filled with cancellous bone. (c) Aspect at one year, immediately after six implant placement.

Fig. 2: Combination of soft-tissue and hard-tissue procedures in lower-jaw reconstruction 1/3. ( $a$ and b) Pre- and post-operative results of the procedure, after scalp rotation flap and bone grafting. (c and d) Pre- and post-operative results after extensive bone grafting. (e) Positioning of the bone grafts in the chin region. (f) Final result of the lower jaw reconstruction after removal of the contention device.

Fig. 3: Combination of soft-tissue and hard-tissue procedures in lower-jaw reconstruction 2/3. (a) Pre- and post-operative results of the soft-tissue and bone reconstruction, with drawings by Paul Tessier planning the scalp rotation flap. (b) Pre- and post-operative result of bone grafts in the lower jaw.

Fig. 4: Complex maxilla reconstruction using multiple grafts (see text). (a) Pre-operative 3D scan of the face with absence of maxilla. (b) Pre- and post-operative results with multiple grafts. (c) Post-operative result with maxilla, orbit, malar and nose reconstruction. 


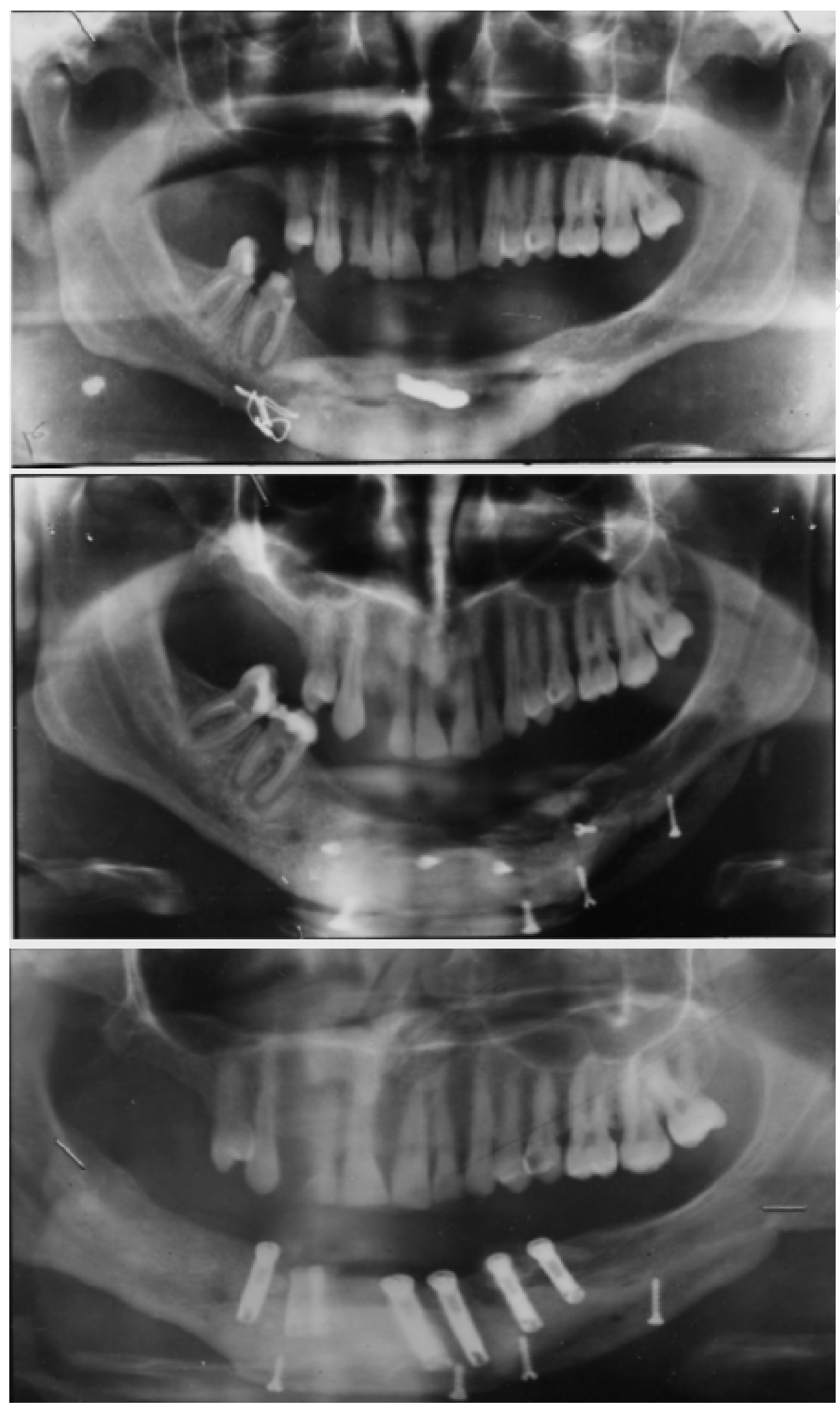




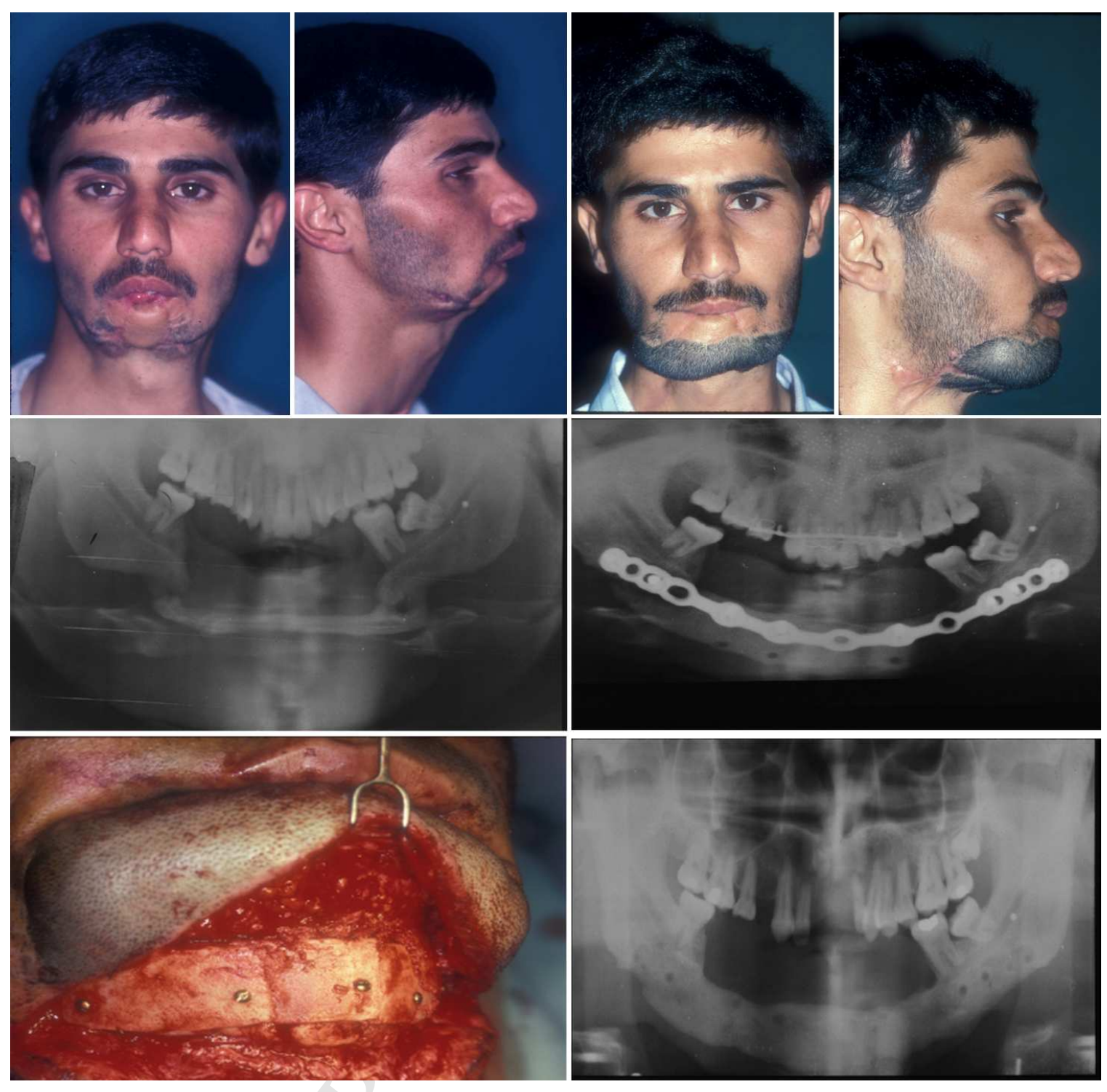




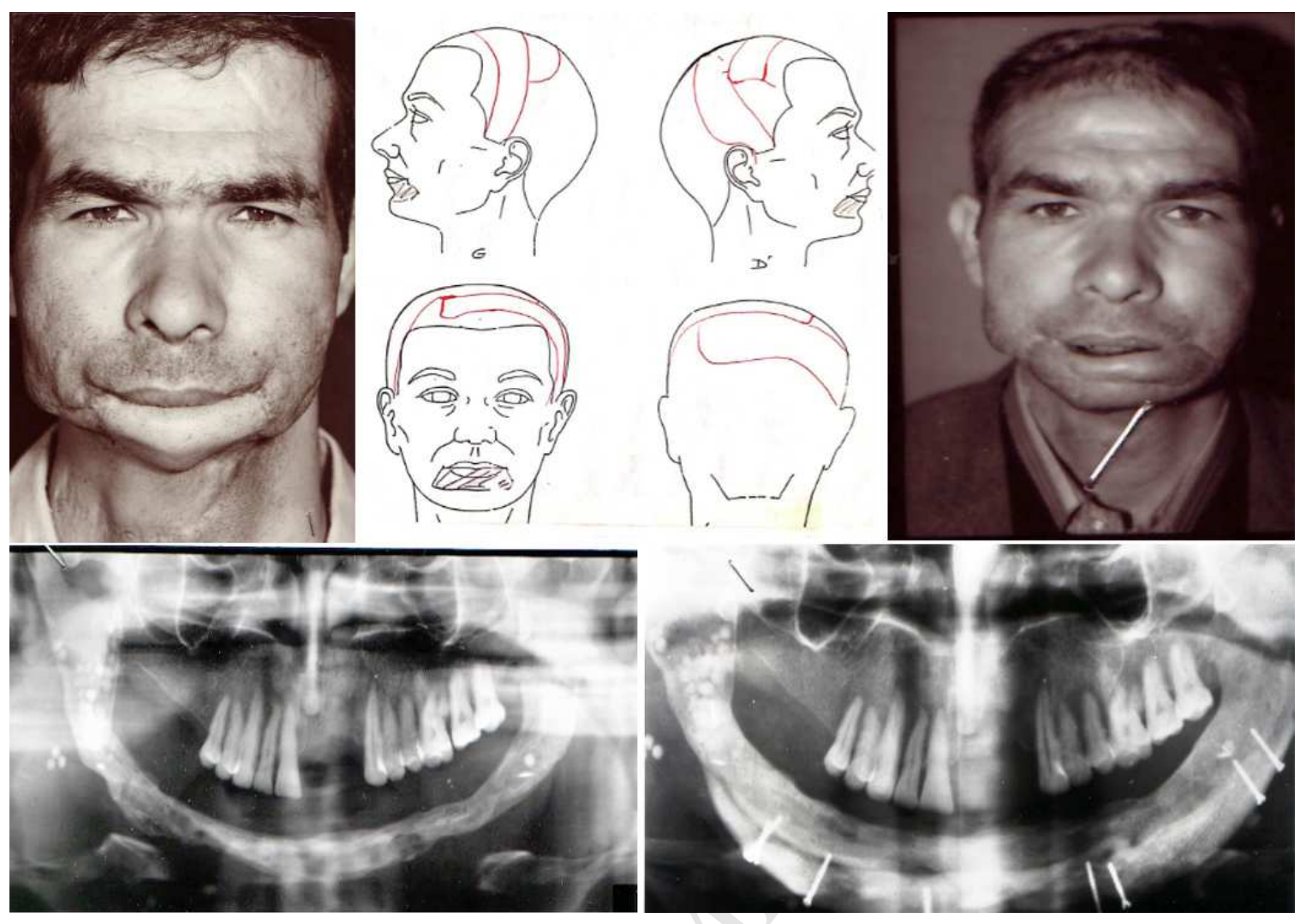



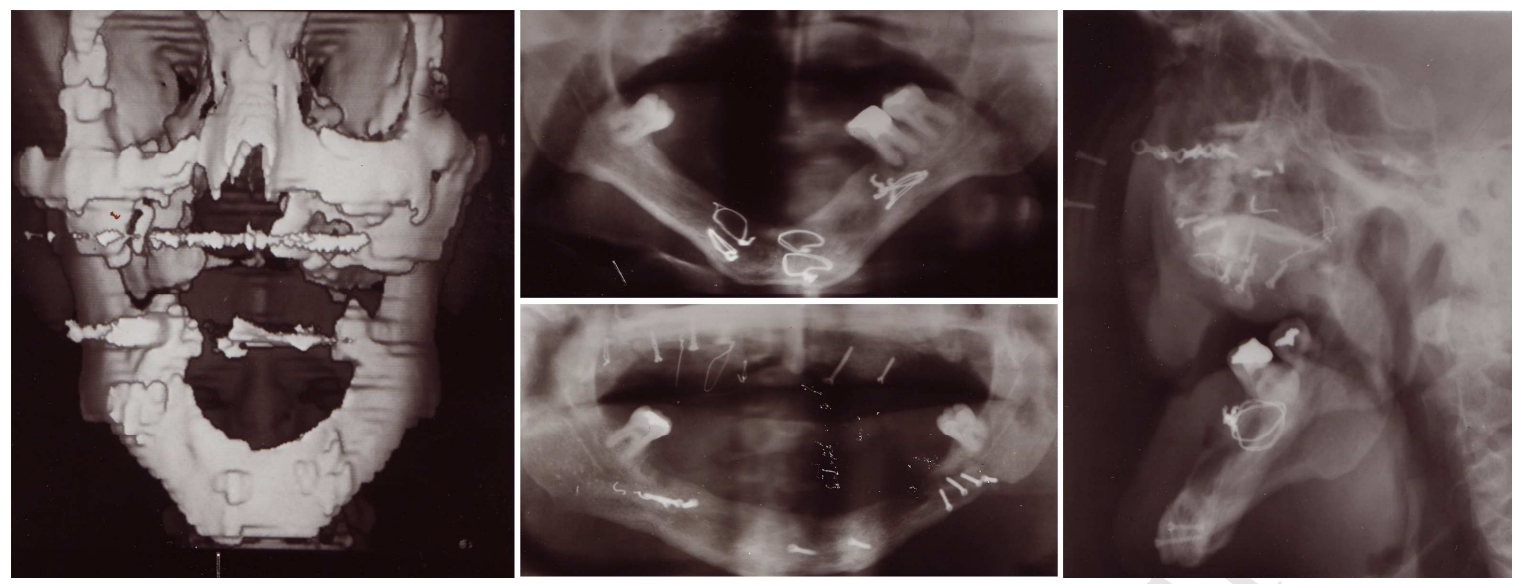
- Detailed account of Paul Tessier's approach to post-war maxillofacial injuries;

- Importance of pre-operative 3D step by step planning;

- Protocol: implants 6 months after soft tissue and bone reconstruction;

- Local flaps preferred to free flaps. 